\title{
Anatomical Alterations Following Resurfacing Hip Arthroplasty
}

\author{
K Sivananthan, FRCS, KJ Drabu*, FRCS \\ Department of Orthopaedics, Kuala Lumpur Hospital, Kuala Lumpur, Malaysia. \\ *Department of Orthopaedics, East Surrey and Redwood Hospitals, Surrey, United Kingdom
}

\begin{abstract}
The number of hip replacement procedures in the United States is expected to increase four-fold by 2030. Younger patients, those under 65 years old, are expected to account for $53 \%$ of hip replacements in 2030 , compared to $44 \%$ in 2005 . As midterm review results are becoming available worldwide now, the problem that perplexes surgeons is the alteration of limb length which has been an ancillary goal of Total Hip Replacements. The lack of modularity in neck lengths and offsets in resurfacing arthroplasty clearly limits the change in limb lengths achievable for the hip. The goal of this study is to scrutinize the various parameters that affect implant seating in resurfacing arthroplasty and to determine the alteration of limb length achievable during surgery.
\end{abstract}

Key Words:

Total Hip Replacement (THR), Resurfacing Arthroplasty (SRA)

\section{INTRODUCTION}

The number of hip replacement procedures in the United States is expected to increase by four-fold by $2030^{1}$. Younger patients, those under 65 years old, are expected to account for $53 \%$ of hip replacements in 2030, compared to $44 \%$ in $2005^{2-4}$. This group of patients in particular causes a dilemma for the arthroplasty surgeon as they will probably outlive the implant ${ }^{5}$. The recent explosion in hip surface replacement arthroplasty (SRA) is partly due to its promise of being a more bone conserving procedure with excellent wear rates of the implant ${ }^{6}$. Furthermore the ease of revising a failed femoral component of SRA compared to a standard stem is a pivotal factor in decision making for the younger arthritic patient ${ }^{7}$.

As midterm review results for resurfacing arthroplasty are becoming available worldwide now, the problem that perplexes surgeons is the alteration of limb lengths during surgery, which is easily achieved in total hip arthroplasty (THA $)^{7,8}$. In THA, there are various components to mix and match during trial implantations in surgery to determine the final implant, but SRA is limited by the lack of modularity and its precise component fit of the implants. This lack of modularity in resurfacing arthroplasty clearly limits the change in limb lengths achievable during this procedure?

The primary goal of this study is to analyze various parameters that alter implant seating in resurfacing arthroplasty, with special emphasis on their effects on neck length variations. It is known that neck lengths and offsets are directly related to variations in limb lengths during hip arthroplasty ${ }^{2,10}$.

\section{MATERIALS AND METHODS}

For this study, seventy eight patients who underwent resurfacing arthroplasty were analyzed. Sixty of the operations were performed in England between January to May 2006 by either the main author or the co author, while the remaining eighteen were performed in Malaysia by the main author from November 2006 to June 2008. The patients in England had a either a Birmingham Hip Replacement (BHR from Midlands Medical) or the Articular Surface Replacement (ASR from Depuy) ) implants. The selection was made randomly by the hip surgeon concerned. All the patients in Malaysia had the Articular Surface Replacement implants.

All patients were chosen and deemed suitable candidates by various clinical and biomechanical parameters. Those with surface arthroplasty risk index (SARI) more than 3 were excluded from the study. SARI was based on a six point scoring system (Table I) with a score $>3$ representing a 12 fold increase risk in early failure or adverse radiological changes.

Patients with acetabular deficiency and osteoporosis were also excluded from the study. Acetabular deficiencies deem the initial implant stability unpredictable. In these cases, cementless THR with screw fixation of the cup were preferred. Patients who were suspected to be at a higher risk for osteoporosis were analyzed for their mineral density levels with a DEXA scan before surgery. Amongst them were women who were post-menopausal, elderly people $(>70)$, a 
family history of osteoporosis and patients who have been on long-term steroids.

For purposes of standardization, all the anteroposterior hip radiographs were taken with the hips in approximately 15 degrees of internal rotation. The various parameters were measured from the preoperative and first post-operative radiographs of the patient. (Fig 1). The inter teardrop line (Line A) is a line joining the teardrops of both hips. Line B is the line perpendicular to line A drawn from the teardrop. The vertical hip centre (VHC) is the perpendicular distance $(\mathrm{mm})$ from the centre of rotation of the hip to line A. The horizontal hip centre (HHC) is the perpendicular distance from $\mathrm{B}$ to the hip centre of rotation.

On the femoral side, a line was drawn along the axis of femur shaft and extended proximally. The horizontal femoral offset (HFO) is the perpendicular distance ( $\mathrm{mm}$ ) from the centre of rotation to the femoral shaft line, and the vertical femoral offset (VFO) is the perpendicular distance from the centre of rotation to the lowest point of the lesser trochanter (line $\mathrm{C}$ ). Neck length (LL) is the perpendicular distance from the inter teardrop line (line A) to the lesser trochanter line $(\mathrm{C})$. The neck shaft and stem shaft angles are determined in relation to the femoral shaft line.

All the measurements were performed by the main author and comparisons were made between the pre operative and first post operative radiographs. These values were thence corrected for a ten percent magnification. Statistical analyses were done with the SPSS software, and the aid of a statistician. The noted differences were calculated using a two sample t-test with a $\mathrm{p}$ value of $<0.005$ considered to be significant ${ }^{11}$.

\section{RESULTS}

There were 38 men and 22 women operated in England, with a mean age (and standard deviation) of $47.0 \pm 7.8$ years (range, 30.1 to 64.2 years), a mean weight of $83.3 \pm 17.6 \mathrm{~kg}$ (range 52 to $126 \mathrm{~kg}$ ), a mean height of $174.5 \pm 8.6 \mathrm{~cm}$ (range 157 to $193 \mathrm{~cm}$ ), and a mean body mass index of $27.3 \pm 5.3$ (range, 20.5 to 44.8 ). Forty-one of these patients had a asymptomatic contralateral hip with normal radiological appearance.

In Malaysia, there were four men and fourteen women operated, with a mean age of $54.2 \pm 11.8$ years (range, 28.0 to 70.7 years), a mean weight of $86.8 \pm 16.1 \mathrm{~kg}$ (range 48 to $119 \mathrm{~kg}$ ), a mean height of $165.6 \pm 8.4 \mathrm{~cm}$ (range 145 to 180 $\mathrm{cm}$ ), and a mean body mass index of $31.9 \pm 6.4$ (range, 19.5 to 42.3). Eleven of these patients had a radiographically normal contralateral hip without any arthritic symptoms.

Compared with the preoperative value, there was no significant change in the neck length since the mean neck length difference was only $-1.9 \mathrm{~mm}(1.9 \mathrm{~mm}$ shorter after surgery). The mean HHC difference was - $4.5 \mathrm{~mm}$, indicating the femur were medialized by a mean of $4.5 \mathrm{~mm}$. The mean VFO difference was $3.70 \mathrm{~mm}$. The mean angle differences (the stem shaft versus the neck shaft angles) was 5.71 degrees, indicating that the implant was inserted in a slightly more valgus position on to the femoral neck. (Table II).

\section{DISCUSSION}

Precise reconstruction of the hip in arthroplasty is essential for the success of this procedure. In particular, a favourable clinical outcome is associated with optimal femoral offset and restoration of leg length. To facilitate the surgeon in achieving this goal in THA, different implant geometries, modularity of the implants used and computer navigation systems are now available. SRA is viewed as a more anatomical procedure, since the small amount of bone resected from the femoral head leaves the proximal femur virtually intact ${ }^{12}$.

The biomechanics in SRA is arguably more complex than THA as there is no option of changing the offsets in the implant. A few studies comparing biomechanical reconstruction by SRA and THA have been published. The authors concluded that THA may be more suitable than SRA in the presence of significant pre-operative leg-length inequality ${ }^{2,3,15-18}$. Compared to THA, SRA does not offer modular components to help create desired offsets thus greatly limiting the options available for the surgeon.

Table I: The surface arthroplasty risk index (SARI)

\begin{tabular}{|lc|}
\hline & Points \\
\hline Femoral Head Cyst $>1 \mathrm{~cm}$ & 2 \\
Patient Weight $>82 \mathrm{~kg}$ & 2 \\
Previous Hip Surgery & 1 \\
UCLA Activity level $>6$ & 1 \\
Maximum score & 6 \\
\hline
\end{tabular}

Table II: Difference in various parameters before and after surgery

\begin{tabular}{|lccc|}
\hline Parameter & Mean $(\mathbf{m m})$ & Minimum $(\mathbf{m m})$ & Maximum $(\mathbf{m m})$ \\
\hline NL ( Neck length) & $-1.9+/-5.1$ SD & -22 & 15 \\
VHC (Vertical Hip centre) & $5.5+/-4.07$ SD & -3 & 15 \\
HHC (Horizontal Hip Centre) & $-4.5+/-5.3$ SD & -16 & 3 \\
VFO (Vertical Femoral Offset) & $3.7+/-5.9$ SD & -20 & 15 \\
HFO (Horizontal Femoral Offset) & $1.2+/-6.5$ SD & -8 & 14 \\
\hline
\end{tabular}




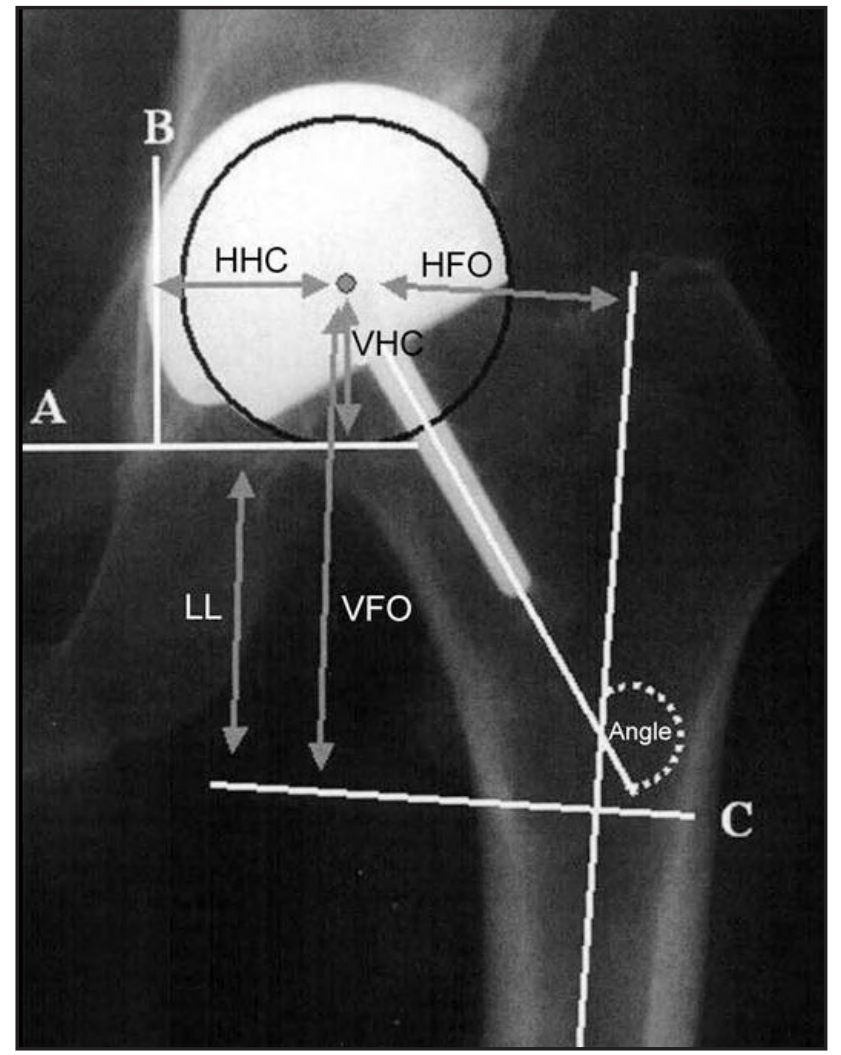

Fig. 1: Various parameters measured from plain radiographs of the proximal femur following resurfacing hip arthroplasty.

In SRA the cup size is determined by the size of the femoral component. This precise articulation needed for an ideal diametral clearance negates the possibility of changing cup sizes. However, this study shows that the main factor in changing the neck length is the amount of superior reaming done whilst preparing the acetabular cup. This is shown by the significant change in the vertical hip centre (VHC) and vertical femoral offset (VFO) in relation to the noted changes in neck length. This difference however is only marginal and cannot be used to correct significant limb length discrepancies. The results of this study also shows that this slight valgus positioning of the implant (up to 10 degrees) has no bearing on the limb length variation post operatively. The outcome in SRA depends on restoration of the proximal femur anatomy. Limb-lengthening of a few millimetres can be achieved and the few cases where there were more lengthenings were probably Arthritic hips that are associated with $>1$ inch of limb-shortening or that have a comparatively diminished horizontal femoral offset may be better served by a contemporary THA than by SRA. These biomechanical limitations should be considered in the selection of hips for resurfacing.

Of these seventy eight cases performed there were no periprosthetic neck of femur fractures although this is a known complication of this procedure. The reported incidence of notching can be as high as $23 \%$ and this is why the NICE (National Institute of Clinical Excellence) guidelines in UK require a surgeon to be formally trained in this procedure before embarking on it. Two patients had an early post operative infection, which resolved with antibiotics and debridements. There were no chronic infections in our study and all patients were ambulating unaided by three months of surgery.

This study had several limitations. Patient selection could not be randomized as most patients referred for resurfacing would not accept a total hip replacement. Because of this, the investigational device did not include a concurrent control group. The parameters were measured on standardized plain radiographs. The limitations of such planar analysis include the potential for variability in femoral rotation that would affect the projection of the neck-shaft angle, the horizontal femoral offset, and to a lesser degree the vertical femoral offset.

\section{CONCLUSION}

In conclusion, SRA remains a very promising option for early arthritis where no significant limb length discrepancy has occurred. As noted in this study, the alteration of neck length is only limited to about $2 \mathrm{~mm}$ and this too is governed by the amount and angle of reaming done into the acetabulum superiorly. This proves that the implant is very anatomical and the limb length is only minimally altered post operatively. It never the less is a very favourable option for young arthritic patients who may outlive their implants.

\section{ACKNOWEDGEMENT}

No benefits in any form have been received or will be received from a commercial party related directly or indirectly to the subject of this article. The statistical analysis of this study was done by Ms. Janice Flemming of Depuy International, London. 


\section{REFERENCES}

1. Amstutz HC. Hip resurfacing arthroplasty. J Am Acad Orthop Surg 2006;14(8), 452-3.

2. Silva M, Heisel CL, Dela Rosa MA, Schm. A randomised study comparing total hip resurfacing and total hip arthroplasty alzried TP. The biomechanical results of total hip resurfacing arthroplasty. J Bone Joint Surg 2004;86-A: 40-6.

3. Loughead JM, Chesney D, Holland JP, McCaskie AW. Comparison of offset in Birmingham hip resurfacing and hybrid total hip arthroplasty. J Bone Joint Surg 2005: 87-B: 163-6.

4. Mont MA, Ragland PS, Etienne, G, Seyler, TM \& Schmalzried, TP Hip resurfacing arthroplast. J Am Acad Orthop Surg 2006; 14(8): 454-63.

5. Treacy RB. To resurface or replace the hip in the under 65-year-old: the case of resurfacing. Ann R Coll Surg Engl 2006; 88(4): 349-53.

6. Amstutz HC, Thomas BJ, Jinnah R, Kim W, Grogan T, Yale C. Treatment of primary osteoarthritis of the hip. A comparison of total joint and surface replacement arthroplasty. J Bone Joint Surg 1984; 66-A: 228-41.

7. Daniel J, Pynsent PB, McMinn DJ. Metal-on-metal resurfacing of the hip in patients under the age of 55 years with osteoarthritis. The Journal of bone and joint surgery 2004: 86-B: 177-84.

8. Konyves A, Bannister GC. The importance of leg length discrepancy after total hip arthroplasty. J Bone Joint Surg 2005; 87-B: $155-7$.

9. Howie DW, McGee MA, Costi K, Graves SE. Metal-on-metal resurfacing versus total hip replacement: the value of a randomized clinical trial. Orthop Clin North Am 2005; 36:195-201.

10. Girard J, Lavigne M, Vendittoli PA, Roy AG. Biomechanical reconstruction of the hip: J Bone Joint Surg 2006; 88-B: 6.

11. Everitt BS. Cambridge Dictionary of Statistics 2002 (2nd Edition).

12. Beaule PE. Removal of acetabular bone in resurfacing arthroplasty of the Hip. J Bone Joint Surg 2006; 88-B, 838.

13. Beaule PE, Amstutz HC. Orientation of the femoral component in surface arthroplasty of the hip. J Bone Joint Surg 2005; 87-A: 1162.

14. Beaule PE, Campbell PA, Hoke R, Dorey F. Notching of the femoral neck during resurfacing arthroplasty of the hip: a vascular study. J Bone Joint Surg 2006; 88-B: 35-9.

15. Beaule PE, Harvey N, Zaragoza E, Le Duff MJ, Dorey FJ. The femoral head/neck offset and hip resurfacing", J Bone Joint Surg 2007; 89-B: 9-15.

16. Robb JE, Rymaszewski LA, Bentley HB, Donnan PT. Reliability of the acetabular teardrop as a landmark. Surg Radiol Anat. 1991; 13: 181-5

17. Steinberg B, Harris WH. The offset problem in total hip arthroplasty. Contemp Orthop 1992; 24: 556-62.

18. Long JP, Bartel DL. Surgical variables that affect the mechanics of a hip resurfacing system. Clin Orthop Relat Res 2006; 453: $115-22$. 